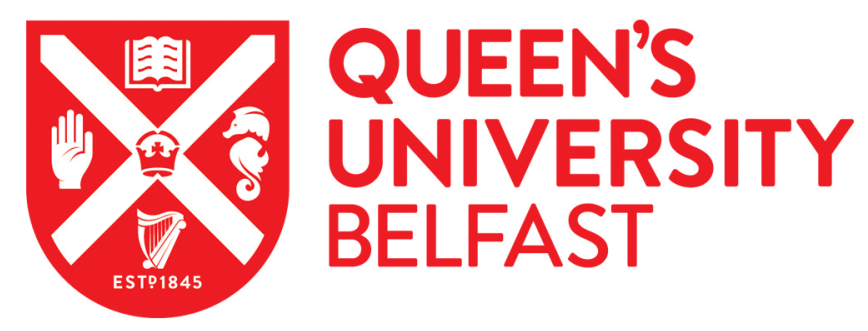

\title{
Key components of supporting and assessing decision making ability
}

Webb, P., Davidson, G., Edge, R., Falls, D., Keenan, F., Kelly, B., McLaughlin, A., Montgomery, L., Mulvenna, C., Norris, B., Owens, A., \& Irvine, R. S. (2020). Key components of supporting and assessing decision making ability. International Journal of Law and Psychiatry, 72. https://doi.org/10.1016/j.ijlp.2020.101613

\section{Published in:}

International Journal of Law and Psychiatry

\section{Document Version:}

Peer reviewed version

\section{Queen's University Belfast - Research Portal:}

Link to publication record in Queen's University Belfast Research Portal

\section{Publisher rights}

(C) 2020 Elsevier Ltd.

This manuscript is distributed under a Creative Commons Attribution-NonCommercial-NoDerivs License

(https://creativecommons.org/licenses/by-nc-nd/4.0/), which permits distribution and reproduction for non-commercial purposes, provided the author and source are cited.

\section{General rights}

Copyright for the publications made accessible via the Queen's University Belfast Research Portal is retained by the author(s) and / or other copyright owners and it is a condition of accessing these publications that users recognise and abide by the legal requirements associated with these rights.

Take down policy

The Research Portal is Queen's institutional repository that provides access to Queen's research output. Every effort has been made to ensure that content in the Research Portal does not infringe any person's rights, or applicable UK laws. If you discover content in the Research Portal that you believe breaches copyright or violates any law, please contact openaccess@qub.ac.uk. 
Title: Key components of supporting and assessing decision making ability

Author names and affiliations: Paul Webb ${ }^{a}$, Gavin Davidson ${ }^{b}$, Rosalie Edge ${ }^{c}$, David Falls ${ }^{a}$, Fionnuala Keenan ${ }^{a}$, Berni Kelly ${ }^{b}$, Aisling McLaughlin ${ }^{b}$, Lorna Montgomery $^{\mathrm{b}}$, Christine Mulvenna ${ }^{\mathrm{c}}$, Barbara Norris ${ }^{\mathrm{c}}$, Aine Owens ${ }^{\mathrm{c}}$, Rebecca Shea Irvine ${ }^{b}$

aPraxis Care, 25-31 Lisburn Road, Belfast, Northern Ireland, BT9 7AA, UK

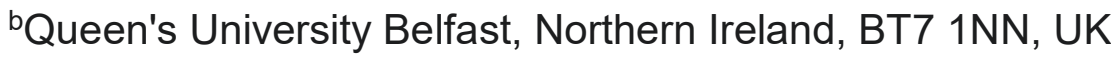
'Mencap NI, 5 School Road, Newtownbreda, Belfast, Northern Ireland, BT8 6BT, UK Corresponding author: Paul Webb, Research Manager, Praxis Care, 25-31 Lisburn Rd, Belfast, Northern Ireland, BT9 7AA, UK. Email: paulwebb@praxiscare.org.uk

Email addresses: Paul Webb paulwebb@praxiscare.org.uk, Gavin Davidson g.davidson@qub.ac.uk, Rosalie Edge Rosalie.Edge@mencap.org.uk, David Falls ad.falls@outlook.com, Fionnuala Keenan fionnualakeenan@live.co.uk, Berni Kelly b.r.kelly@qub.ac.uk, Aisling McLaughlin aisling.mclaughlin@qub.ac.uk, Lorna Montgomery I.montgomery@qub.ac.uk, Christine Mulvenna Christine.Mulvenna@mencap.org.uk, Barbara Norris c/o MaryAnne.Webb@mencap.org.uk , Aine Owens c/o jonathan.craig@mencap.org.uk, Rebecca Shea Irvine Rebecca.Irvine@qub.ac.uk

Funding information: This research was funded as part of the Disability Research on Independent Living \& Learning (DRILL) Programme. DRILL was fully funded by 
the Big Lottery Fund and delivered in partnership by Disability Action, Disability Rights UK, Disability Wales and Inclusion Scotland. The DRILL Programme was led by disabled people and funded coproduced research and pilot projects focused on exploring how disabled people can live as full citizens and take part socially, economically and politically.

Declaration of Interest: Gavin Davidson is the Praxis Chair of Social Care at Queen's University Belfast and this post is part funded by Praxis Care.

Accepted for publication in the International Journal of Law and Psychiatry on 20/07/20. 
Title: Key components of supporting and assessing decision making ability

\section{Abstract}

People's ability to make decisions may be impaired for a wide range of reasons, including by mental health problems and learning disabilities. Individual autonomy, the ability to make decisions about our own lives, is a fundamental tenet of democratic societies. This has been reinforced by laws governing substitute and supported decision making and most significantly by the United Nations Convention on the Rights of Persons with Disabilities (UNCRPD). Article 12 of the UNCRPD requires everyone to have equal recognition before the law and, to achieve this, the necessary support and safeguards must be available. There has been considerable debate about the important theoretical and philosophical issues involved and growing research about the practice complexities of supporting and assessing decision making ability or mental capacity. This article aims to present some of the key components of the support and assessment process to inform further service development and training in this area. The key components were identified as part of a qualitative, participatory research project which explored the decision making experiences of people with mental health problems and/or learning disabilities. The conventional approach to the assessment of capacity is to consider four main components, whether the person is able to: understand, retain, use and weigh, and communicate the information needed to make the decision at that time. The findings from this research study suggest that people generally don't usually talk about their experiences of decision making in terms of these four components and approaches to supporting people to make decisions don't necessarily break the support down to explicitly address the assessment process. However, considering support for all 
aspects of the functional test may be helpful to ensure it is as comprehensive as possible. The challenges involved in providing effective support and assessing decision making ability are discussed and the article concludes with some of the implications for training, service development and practice.

\section{Keywords}

Mental capacity; mental health; intellectual disabilities; learning disabilities;

UNCRPD; assessment; training

\section{Introduction}

Individual autonomy, the ability to make decisions about our own lives, is a fundamental tenet of democratic societies, and this has been reinforced by laws governing substitute and supported decision making. There has been considerable debate about the important legal, theoretical and philosophical issues involved and growing research about the practice complexities of supporting and assessing decision making ability or mental capacity.

Supported decision making has been defined by the Victorian Law Reform Commission (2011, p.19) as, "An approach to decision making that involves providing a person with impaired capacity the support they need to make their own decision. It is often contrasted with substitute decision making, where a decision is made on behalf of a person who is unable to make that decision".

There are a number of rights based, effectiveness and pragmatic arguments for providing supported decision making. Article 12 of the United Nations Convention on 
the Rights of Persons with Disabilities (UNCRPD) (United Nations, 2006) requires everyone to have equal recognition before the law and, to achieve this, the necessary support and safeguards must be available. Consequently, States must "take appropriate measures to provide access by persons with disabilities to the support they may require in exercising their legal capacity" (Article 12(3)). The Article requires the development of a positive range of supports to enable people to fully exercise their rights and, wherever possible, prevent the need for substitute decision making (Quinn, 2010). This is sometimes referred to as the right to legal capacity and it is important to acknowledge that people can and should retain legal capacity, and their other rights, regardless of whether they have the relevant decision making ability or mental capacity.

This paper will identify some of the key components of the support and assessment process and forms part of a larger project which examines the experiences, approaches and preferences of people making decisions with support (Webb, Davidson, Edge et al., 2020). This paper provides a more specific exploration of findings that may relate to the assessment of capacity and how that could inform the design, co-design and provision of support. It is based on research conducted in Northern Ireland (NI) where the Mental Capacity Act ( $\mathrm{NI})$ became statute law in May 2016 and was partially implemented in 2019 (although the date for full implementation has not yet been set). In contrast to other countries this law will replace rather than operate in parallel with mental health legislation. A core principle of the new Act is that individuals are "not to be treated as unable to make a decision...unless all practicable help and support to enable the person to make a decision about the matter have been given without success" (Article 1(4)). There is 
emerging but limited research evidence available about disabled people's experiences of the range of approaches provided to support decision making; what approaches work for whom; and what people's preferences are for support (Carney, 2014; Bigby et al., 2017; Kokanovic et al., 2018; National Institute of Health and Care Excellence, 2018; Devi et al., 2019). This evidence is needed to inform the Code of Practice for the new Act and the wider implementation process.

The overall aim of this research was to inform how the new support principle arising from the 2016 Act should be implemented in practice (Webb, Davidson, Edge et al 2020 p. 3). The project was designed to explore how people with mental health issues and/or learning disabilities have, or have not, been supported to make their own decisions. The term 'learning disabilities' was used, instead of the more commonly used international term 'intellectual disabilities', as this was the preference of the participants and peer researchers involved. It is anticipated that these findings could also inform service development and training in this area.

\subsection{The Concepts of Autonomy and Mental Capacity/Decision Making Ability}

The central principle underlying supported decision making is autonomy, that "no person should have another person appointed to make a decision on their behalf, if they could make the decision themselves with assistance and support" (Chartres and Brayley, 2010, p. 1).

Supported decision making should be considered as an important part of a continuum of decision making from autonomous decision making through to substitute decision making. Historically law and policy have tended to focus on either 
end of the spectrum and have approached capacity as if people are either globally capable or incapable, but most people require some level of support with many aspects of decision making. Supported decision making may provide an alternative to the substitute decision making in which decisions are made by a third-party, "who generally base decisions on the perceived objective best interests of the person" (Flynn \& Arnstein-Kerslake, 2014). Supported decision making is based on the belief that "every human being is communicating all the time and that this communication will include preferences" (Beamer \& Brookes, 2001, p.4). The way in which these preferences are interpreted and responded to is therefore important, especially in circumstances when decision making ability may be impaired. Chartres and Brayley (2010) suggest that supported decision making has benefits for individuals, families and communities including the enhancement of personal autonomy and the feeling of control that people have over their own lives, and more generally it can contribute to a more inclusive approach to disability policy and support.

\subsection{Literature on Assessing Mental Capacity}

The majority of people are presumed to be capable of making their own decisions.

However, there are some people with a disability or illness who, without support, would be assessed as incapable of making certain decisions, and so there needs to be some process of identifying when this is happening (Appelbaum, 2007) and providing the most effective support for decision making.

The Mental Capacity Act 2005 (MCA 2005), for England and Wales, outlined fundamental principles relating to how, and in what situations, decision making capacity should be assessed. Firstly, capacity assessments should occur when an 
individual's inability to make the decision results from a disturbance of the mind or brain, on either a permanent or temporary basis. Secondly, in establishing an individual's capacity, that individual's ability to understand, retain, use and weigh the relevant information presented to them should be assessed. The Mental Capacity Act (Northern Ireland) 2016 (MCA 2016) added that, in addition to the ability to use and weigh the information, the person must be able to appreciate the relevance of that information but it is unclear what implications, if any, this may have in practice. In both legal frameworks, it is highlighted that mental capacity is time and event specific. The individual must be unable to make the decision at the time the decision is required. Overarching these principles is the concept of 'best interests'. Best interests decisions relate to the method and focus of decision making for an individual who lacks capacity to make a particular decision. The MCA 2005 specifies that any best interests decision must be made to reflect the views, opinions and cultural beliefs of the individual who lacks capacity to make the decision, without the influence of personal preferences, beliefs or judgements of the decision maker. The MCA 2016 adds that in considering best interests, there must be special regard to the person's past and present wishes and feelings, their beliefs and values and any other factors that they would be likely to consider if able to do so (Section 7(6)).

In general law and guidance also specifies that an assessment of capacity must not be done solely on the basis of a person's age, appearance, condition or behaviour. For example, the diagnosis of particular illness such as dementia or psychotic disorder should not be confused with the determination of capacity (Appelbaum, 2007). The importance of context, relationships and worker skill must be also 
considered (Dawson \& MacDonald, 2000). Incapacity is seldom absolute, it often fluctuates and assessments must always be dynamic and subject to change.

A review of the literature relating to mental capacity issues, and the practical application of mental capacity legislation was conducted by the Mental Health Foundation (2012). Factors associated with impaired capacity were seen to be specific to the illness or disability and consequently varied according to service user group; specific findings have been made in relation to capacity issues and mental health (Goss et al., 2008; Hamann et al., 2009; Patel and Bakken, 2010), learning disability (Antaki et al., 2008; Dunn et al., 2010) and dementia (Gregory et al., 2007; Menezes and Tadros, 2008). More generally, it was found that factors involving the assessment of capacity which resulted from a person's emotional state or physical functioning tended not to be accounted for within standardised capacity assessments (Mackenzie and Watts, 2011). Finally, whilst divergences between policy and practice, often at the institutional level, were seen to mitigate against good practice in health and social care settings, there was evidence of a cultural shift towards more ethical practice under the MCA 2005 in England. Further improvements were called for within social and health care settings, although it was suggested that these are more likely to result from a cultural shift, according to the principles of the MCA 2005, rather than through rigid adherence to policy.

As noted incapacity to make a decision can only be established if all practicable steps to help the individual to make the decision autonomously have been attempted without success. The understanding and practice of supported decision making is also evolving. 


\subsection{Literature on Supporting Decision Making}

Supported decision making involves providing a person with impaired capacity with the support they need to make a decision. Supports may include a wide range of approaches such as information, independent advocacy or supportive networks of friends and family. It is most commonly provided on a voluntary basis by someone with whom the individual has a long-term relationship based on trust and may have an outcome that is verbal or written (Carter, 2009). Supports may include assisting the individual in: formulating an opinion; considering a range of choices and making a selection; engaging in a decision making process with other parties; and taking action to implement a decision (Bach \& Kerzner, 2010).

In 2015, a review of the international literature published between 2000 and 2011 related to supported decision making identified four main themes within the studies: stakeholders' views on supported decision making; barriers to the implementation of supported decision making; ways to improve implementation; and the impact of supported decision making (Davidson et al., 2015). An important theme in the literature is that decision making is a critical component of personhood and citizenship and important for the realization of equal rights (Bach \& Kerzner, 2010; Flynn \& Arnstein-Kerslake, 2014). It has been argued that Article 12 (UNCRPD), requires a shift away from a preference for substitute decision making and the development of a range of support options to enable people to exercise their rights and prevent the need for substitute decision making to the greatest extent possible (Quinn, 2010; Devi, Bickenbach \& Stucki, 2011). It also requires moving away from the "traditional" approach where a person may be deemed incapable based solely on the fact that they have an impairment, toward a "functional test", by which a person is "considered incapable, if, by reason of the disability, he or she is unable to perform a 
specific task" (Devi, Bickenbach \& Stucki, 2011, p. 253). The interpretation of Article 12 has been the subject of many academic analyses regarding legal capacity and mental capacity (Devi, Bickenbach \& Stucki, 2011; Morrissey, 2012; Devi, 2013; Dawson, 2015; de Bhailís \& Flynn, 2017; Arstein-Kerslake et al., 2017). ArsteinKerslake et al. (2017), argue that while many have written about when to recognise legal capacity, fewer have addressed how to protect it without establishing a mental capacity threshold or how the exercise of legal capacity is understood.

There is also a growing body of literature on models and experiences of supported decision making (Bigby et al., 2017; Kokanovic et al., 2018) and on relationships with individuals who offer support in the decision making process (Watson \& Joseph, 2015).

Regardless of the specific approach used the key components of empowerment, choice and control are deemed necessary to facilitate supported decision making (Carter, 2009), within which the principles of person centredness and the provision of clear information in order to simplify the decision making process, have been highlighted (Wong et al., 2000; Elliot et al., 2005; Dowling et al., 2007; Carter, 2009; Flynn \& Arstein-Kerslake, 2014). However, in practice the process of assessing decision making ability is arguably complex and subject to debate.

\subsection{Practice Complexities}

Debate continues around which professional disciplines are best placed to undertake the assessment of mental capacity and how best to equip staff for this role. Practitioners have identified a lack of; confidence, knowledge and competence to 
complete a mental capacity assessment, (Willner et al, 2007; Ramasubramanian et al, 2011; Samsi et al, 2012, Willner et al, 2013; House of Lords, 2014). There is a recognised need for staff training due to concerns about levels of knowledge; inconsistent practice; and the lack of involvement of service users (Goldsmith et al., 2008; Ahmed et al., 2011). Determining the threshold for assessment and ensuring consistency, within and across the Health and Social Care sector is problematic. Carney and Beaupert (2013) argue that the root of the problem of implementing supported decision making is that it is 'conceptually ill-defined', leaving it open to multiple interpretations. The impartiality of assessments within the healthcare sector has been challenged, and attributed to potential for paternalistic practices among professionals (Donnelly, 2009). More specifically, the influence of perceived risk, which may result from a person deemed to be making an 'unwise choice', or deemed to be at the fringes of decisional capacity can be difficult to assess (Emmett et al, 2013).

In determining who is best placed to offer support, a number of empirical studies have documented the experiences of individuals and supporters in the supported decision making process. One of the key findings has been that 'decision making is a dynamic and interactional process' (Knox, Douglas \& Bigby, 2015, p. 15) and that the relationship between the individual, supporter and the context is at the heart of the process (Knox, Douglas \& Bigby, 2015; Jamieson, Theodore, \& Raczka, 2015). Other potential barriers to implementation include slow progress on legislation reform, high cost of implementation, and a lack of involvement of people that require decision making support in developing the supported decision making practices (Goldsmith et al., 2008; Ahmed et al., 2011; Hoole \& Morgan, 2011; Carney, 2017). 
Concerns regarding safeguarding have also been identified. On occasion, those individuals who lack capacity to make one or more decisions about their own protection are also unable to protect themselves from the malign actions of others. In this context, it is important to ensure that the interests of potential victims without the relevant decision making capacity, are given due consideration within safeguarding processes (Redley et al., 2011). More recently there has also been more consideration of the possible misuse of support in practice, when approaches can move from support to pressure and even coercion (Stone et al. 2020). A further aspect of the emerging literature focuses on the potential of artificial intelligence to inform and support decision making (Kerr and Gruben, 2019) which introduces further complexities.

\section{Methods}

One key objective of this study was to take a look at the key components of supporting and assessing the decision making ability of people with mental health and/or learning disabilities. In order to meet this objective, the data from a larger project which examined the experiences, approaches and preferences of people making decisions with support (Webb, Davidson, Edge et al., 2020) was re-analysed through the four main components of the capacity test. Ethical approval for the study was granted by the School of Social Sciences, Education and Social Work, Queen's University of Belfast.

In order to elicit data, a qualitative, semi-structured interview schedule was informed by the international literature and a multi-disciplinary international advisory group and designed by the research team, which included experts by experience, four peer 
researchers who were employed for the duration of the project. The interview schedule was designed to identify three top-level categories: experiences of making decisions, approaches to support and ideas for future support. Sufficient data was also collected in order to allow for an exploration of the relationship between support, assessment and training. Although the primary role of the peer researchers was to interview people with support from other members of the research team, the peer researchers were also involved in data analysis and dissemination of the results. The peer researchers were recruited and employed by Praxis Care and Mencap NI with successful candidates being trained by members of the research team from Queen's University of Belfast. Peer researchers were recruited as team members because it was felt that they, as experts by experience, would be able to help inform the research design, establish a positive rapport with interviewees and thereby collect better data.

Prior to beginning each interview, the peer researcher, or another member of the research team, gave each interviewee a Participant Information Sheet and discussed it with them. Each participant was therefore aware of the study goals as well as their right to withdraw from the study at any time. Each participant signed a written consent form before each interview. Participants also gave their consent to each interview being recorded and subsequently transcribed.

Forty-one people with mental health and/or learning disabilities were interviewed between November 2017 and January 2018. The forty one people were recruited by research team members from Praxis Care and Mencap NI who managed the fieldwork and made initial contact with potential participants via email, letter, a 
project leaflet or by talking through the project with care staff who were familiar with the research. All participants were interviewed in Praxis Care or Mencap NI units across Northern Ireland. Participants were also selected with due regard being paid to impairment, gender, age and geographical distribution to obtain a wide range of perspectives.

Interview responses were transcribed verbatim with any identifying information being removed. Each interview was assigned a unique ID code. The data was then analysed using thematic analysis (Braun and Clarke, 2006) within NVivo with reference to a coding frame. The coding frame had been developed by the research team who used the frame to assign categories to a sub set of transcripts in order to determine how well the frame's categories mapped on to the data. The results of the data analysis were subsequently presented to interviewees at a 'Participant Event' in order to check how far the researchers' interpretations and thematic analysis were congruent with the interviewees' own experiences.

\section{Results}

The following sections outline the research findings from the study in the context of the four parts of the functional capacity test and the aspects of support which participants reported to be helpful. We also highlight some of the findings relating to training. In the participants' quotes it's identified if the main type of service they were using was either Mencap (MEN) or Praxis Care (PRA) although both organisations support people with learning disabilities and mental health problems. 


\subsection{Understanding Information}

The first key aspect of the capacity test is the ability to understand information. Participants provided accounts of their experiences of understanding information relevant to their decisions and the factors which helped them with understanding. For some, decision making was a daunting experience as they did not understand what was required to make the decision and often relied on others to provide support (which may involve actively approaching others/seeking support/information):

Sometimes scared because I don't really know ... sometimes I don't really understand ... there's ways of going about different things and sometimes I don't know if I'm going to make the right decision, so ... Sometimes I find it hard to ask my brothers and sisters in case I can't do something - I can, but I just don't understand what way to do it, so I don't (MEN006).

Well nearly always make my own decision, but they (staff) would advise me, put me in the right place, but if I don't understand anything they would take over and then they would explain to me what's going on (MEN007).

Well, sometimes if it's difficult to make decisions, like certain situations come across like, you know, it's hard to explain - just things that get difficult and you have to make your own decisions at times - I find that hard so I rely on Praxis for a bit of support in that area, you know (PRA003).

Well sometimes I could be a wee bit stuck and things like that and I would have to get a member of staff to help me out and to talk to me about things, because 
sometimes my brain and my memories doesn't work on their own (laughs), I get help from other people that I know like the staff and all like yourself (MEN009).

\subsubsection{Increasing Participants' Understanding of Decisions}

Negative feelings/experiences around decision making appeared to be dependent on/resolved by getting support from others and having all the necessary information so that they may understand the decision to be made. Approaches which were reported as helpful in increasing an individual's understanding of the decision to be made included focusing on informational support e.g.: providing them with all the necessary information to make the decision; using accessible and familiar formats; tailoring the information to the needs of the individual (e.g. visual information, PowerPoints); writing down information/reminders; reading and explaining to them; and providing practical knowledge and advice.

I didn't really know about it, I just went with the flow at the time. Maybe if I think now, back, I could've ... maybe if they had've asked me, things could be different, but ... That's the way it went (laughs) so it did (MEN006).

To have everything in accessible format, for that person to understand, and to define in what way it is best for that person to understand. So, one format isn't going to help everybody because everybody is different. So it's about making sure everything is set out in different ways for different people (MEN006). 
I think it's important that the person is included in what it is - and sometimes if a person doesn't understand it, then maybe get the information in a different way for that person to understand (MEN006).

Give them more information - if you have all the information that's available, you're going to be in a stronger position to make a correct decision (PRA004).

Reading, reading over it for you to make decisions, reading over it isn't really good for people I don't think, people who has no patience, do you see the way you ask me the questions that was handier than me sitting there reading it and being nervous and you know not know what's going to pop up next, so it helped me to make them decisions there (PRA014).

\subsubsection{Support to Understand Participants' Needs}

Participants outlined the qualities of a good supporter and the value of having someone to talk to particularly someone who was understanding/understood their needs. Skills were also important i.e. being capable of explaining the information in an appropriate fashion.

They need to explain that more to me then l'll understand what they're saying but no one actually knows how to explain that right (MEN003).

Well, I had anxiety and depression at first ... and then ... I was sent ... I had this from day one ... because ... I had a problem with, one ... of the staff from induction 
... yes, because she said something to me and then ever since I got it in my head, don't know what to do, I get frustrated. That's how it begins (MEN001).

\subsection{Retaining Information}

The second aspect of the capacity test is to retain information long enough to be able to make a decision. There were limited examples of this within our data. There were references to needing prompts/reminders for appointments in the past which possibly may have indicated difficulties with retaining information to make certain decisions. Other examples included having someone show participants how to use transport/travel on their own.

I decide myself, but the staff will tell me the day I will do it, then if I forget they would remind me, or I would normally now remind myself, they used to do it at the start (MEN017).

I go to Doctor appointments - just appointments - I go in whenever I have an appointment. Major difficulty is not making the decision, but remembering the date on which to go where (PRA004).

You know say for example telling me to write things in my diary, my mum would, but a lot of the time she has a point because I would forget and I try to plan the week, and I would tend to argue a lot with her and I shouldn't you know, she's only doing it for my own good, but you know that's what parents are for, but children can make decisions about their parents as well, and siblings as well, like they do (MEN017). 
Yeah, if it's anywhere that I didn't know how to get to but I had to go I would get (name removed) to do a dummy run with me, what we call a dummy run, and then I would get him to do that a couple of times with me, and then I would probably try it out on my own, so if I'm going into on my own now I can do it now but I used to have said to (name removed) right I'm going to go into Belfast do you fancy coming with me and he would come with me and show me the route from the Europa bus centre round into City Hall and vice versa, and he's done that with me a couple of times, and the last couple of times l've been able to go around Belfast on my own now without any direction (MEN020).

\subsection{Using and Weighing up the Information}

The third aspect of the capacity act is the ability to appreciate the relevance of information and to use and weigh that information as part of the process of making a decision. The ability to weigh up the pros and cons of a decision and difficulties with decision making in general was highlighted by a number of participants.

Yea, yea. Always been in a split way sometimes you know, should I or should I or what, it's hard. Aye (PRA009).

Mmm ... Sometimes I'm not sure ... whether they're the right ones or not ... no ... or is this appropriate? But mmm ... usually I'm OK, so I am, usually I'm OK (PRA002).

Sometimes they are hard like you know. Putting things off, putting that off, I'm always putting things off usually you know (PRA009). 


\subsubsection{Having the Time to Think about a Decision}

A key factor in assisting participants in weighing up the information was having the time to think about the decision. Overall participants discussed the value of having time to think about the question, the answer and having time to access the information they required while considering the decision. Time pressures generally made decision making more difficult for participants. Some felt that their decision making improved with age.

I wouldn't make very fast decisions. I would ponder over it and be more cautious, very cautious. Well, you would look for the faults first and then make a decision..... I would weigh the whole thing up. I would now 'cause with age comes wisdom. I learnt my lesson and the older you are, you tread cautiously. It comes with age (PRA006).

Or decisions that $\mathrm{mmm}$.... That has to be made quickly - that's confusing sometimes - because you have to think right on the spot and sometimes it's hard to think, because you ... if I do that there, what's going to happen to this and that - so sometimes it's very hard ... (MEN006).

I would be afraid to make the wrong one, if I need to make a decision quick I would need to try and find someone to help me to make that choice (MEN007).

Not letting me have any breathing space to decide, so ... to ponder upon it, to think for myself (PRA003). 
I wouldn't make it quickly but I would certainly give it a good deal of thought before I decide what I was gonna do you know. I would definitely give it a lot of thought. Sometimes I had to make decisions to suit other people you know (PRA007).

\subsubsection{Weighing up a Decision and Possible Outcomes}

The implications/possible outcomes when weighing up a decision were also reported by participants in relation to whether they had made the right or wrong decision.

I don't really have any problems in terms of decision making. I usually can make the, whether it's the right one or not is another thing. Usually can make a decision about what I'm gonna do or what I should do you know but er, I wouldn't say that I had any problems with it you know (PRA007).

Mmm ... if it turns out a good thing then I feel good about it (laughs). So ... that's all I can say about that (PRA015).

Mmm ... depending on the outcome, if it's a decision you make and it has a good outcome then it's a good thing (PRA015).

\subsubsection{Weighing up a Decision: Enablers}

Factors which helped with weighing up decisions included providing limited choices (e.g. multiple choice as opposed to a range of choices).

I find it very hard to make a decision, it's like, you say something and l'll agree with it or I won't agree with it so it's like being given a multiple choice, what would you like? 
For I find it very hard to make a decision on my own..... If somebody gives me a multiple choice, I can make a decision (laughs) (PRA012).

If you say to me, would you like to do that or would you not like to do it, I can make a choice there and say 'yes' or 'no'. (laughs) I've eventually learnt; I used to be unable to not to say that word 'no' (PRA012).

\subsubsection{Weighing up a Decision: Inhibitors}

Conversely, the ability to weigh up information for some was impaired by mental ill health, medication etc.

Since, you know, like, my illness ... can just be a bit indecisive sometimes.

Whenever my health goes down I can be indecisive, but when I'm OK, on better days, I can decide, you know, so ... (PRA015).

I was clean of drugs over there for 2 years but the brain damage was done, it was too late, so I had to come back and be put on medication then, my medication helps me, you see whatever I done to myself I would be hallucinating and hearing things and anxiety and panic attacks all the time, working myself up and very afraid, it affects my decision making then, but sorry go on with the next question (PRA011). 


\subsubsection{Aspects of Support}

Aspects of support. This particular section of the act related to the approach to support provided by others which can be helpful. Parents, friends and colleagues were particularly mentioned in assisting with weighing up the pros and cons of decisions and having someone to bounce ideas off:

Well every day decision making for me I would normally try to decide myself but if I'm struggling to make a decision I would talk it over with my mummy and my daddy, or if it's a work decision I would talk it over with my colleagues and my line manager (MEN013).

Mmmm ... financially, you know, it's helpful to have my daughter to give me her opinion and things..... So I spoke to (daughter's name removed) and I said, do you think I should?

She said, it would be safe enough, you know. So I would go ahead - so that's what I've done, you know. But ... I was a bit iffy until I spoke to (daughter's name) (PRA012).

It's very important for that person to be included in what is decided for them. Because maybe that person might not want to do that - that decision - and they should be asked - and maybe for that person to understand, well maybe that's benefit to them if they do it this way, going to be harder if they do it the other way so maybe it's good to have the ifs and the dos and don'ts of it too. If you don't do that, that's what's going to happen here - so maybe for people to understand that (MEN006). 
They weigh up the pros and cons, they say if I do ' $A$ ' this might happen and ' $B$ ' that, just another person to get feedback from and confidence, sometimes I might not be as confident as I look but sometimes I need somebody to say you can do it $<$ name of interviewee removed> or maybe I shouldn't do it, you know that way (MEN013).

I find it (support) is important because I wouldn't be able to make the major decisions myself (PRA003).

I feel good (when making decisions), and then sometimes I would be a bit unsure and I would ask for their opinions, I would ask for a second opinion, like from my mum or that (MEN017).

Sometimes you know you say to yourself this is gonna get in the road and that is gonna get in the road they come across as the same date so we'll have to postpone one of them you know. l'd usually ask <name removed> or somebody you know, my key worker or someone, what do you think I should do? Ask for advice you know, postpone this one or that one, you know, you know, which would be the best one to go to like (PRA009).

\subsection{Communicating their Decision}

The fourth aspect of the capacity act is not being able to communicate a decision (whether by talking, using sign language or any means). Participants were asked whether they felt individuals should always be supported to make decisions and the 
general consensus was that they should be supported at all times. The reasons included - freewill/independence- they are their 'own person' (MEN016) and can 'make up their own things in their own mind' (PRA013); it can make people feel good/happy; helps them to cope better; its important they are included in what's decided for them (and understand the pros and cons); can help them to make the right decision (when given advice/support); and makes decision making easier. The importance of safeguarding people with a learning disability was highlighted and other issues were identified such as the specific needs of the individual (and using the appropriate accessible information) and the type of decision.

I think everyone has a right to their own independence, so they have a right to say if they wanted support with a decision (PRA015).

It's not that they can't make decisions for themselves, they just might need a bit of support with making decisions (MEN020).

I think it's important for people with a learning disability to have their own choices in life but be supported and be given the option, but obviously they do be to keep them safe too (MEN013).

I think it's important for people to be fully included in the decisions that's made ... so it's hard. So people are fully in control of what they're doing...... because I don't want people to go through what I went through. I like people to have enough information that they can make decisions about things (MEN006). 


\subsection{Participants' General Views about Decision Making Ability and Support}

Participants also spoke generally about their capacity to make decisions. There were variations in reports of capacity to make decisions ranging from everyday decisions through to more complex or serious decisions (e.g. where to live, finances). Overall, participants' capacity/perception of capacity was generally linked to disability, mental ill health or the effects of drugs or alcohol and participants highlighted examples from the present and the past. For some, being aware of the effects of medication/mood made it easy for them not to make decisions as they were aware they didn't have the capacity.

I'm not good at making decisions (PRA012).

If it's to do with my medication and the anxiety it's easy for me to make a decision because I know that I'm not able to do stuff, so I just say no outright (PRA011).

I'm learning disability, I dunno right from wrong you know what I mean? (PRA021).

I know I'm not right, I'm not fit to work and I'm not fit to socialise and I'm not fit to make some decisions for myself (PRA011).

Money wise I am not confident about, like if I had invoices or bills that I had to pay I think I would need assistance from my father to be able to sort that out, but in terms of shopping and getting food for myself and like say this time of year getting stuff for Christmas I am actually happy enough to do that myself (MEN018). 
Well I suppose with my mum and my dad and if I be too, but I'm sure there was, whenever I was younger and that, but deciding what education I was going to go for they would have made that decision there, but it worked out for the best so it did because I didn't have the capacity (MEN013).

\subsubsection{Participants' Views of Support and Partial Decision Making}

Participants did acknowledge that there may be cases where individuals should not be supported/others may have to make decisions (or partial decisions) e.g. not having the capacity; not having enough support (e.g. no family members); when they have been admitted for psychiatric care/mental health has deteriorated; emergency operations/procedures and self-harming. In those circumstances, those who could make the decision included family members and carers (while respecting the individual's wishes). However, in general, there was a sense that individuals should be supported at all times, where possible. Others gave examples in line with poor decision making as opposed to not being able to make decisions e.g. listening to friends rather than parents or staff.

They should be supported all the time, like you know. Obviously I would think, it would be the right thing to do just to support them all the time (PRA016).

The family would make that decision, if I can't make a decision I would count on family to make the decision (MEN007). 
When you're mentally unwell, definitely they should take - not all of your say, but about $80 \%$ of your say off you, just until you get better, and then ... gradually build you back up again to where you were initially before you got ill (PRA001).

There's times when the doctors have to make decisions if you're self-harming which I don't myself and I'm glad they made them decisions because <name of participant removed> wouldn't be here now if they didn't make them (PRA010).

I think so yes, say for example as well if somebody who can talk, who can actually verbally say, but sometimes it's difficult if that person can't talk or can use signs, but actually if that person can't make a decision that they can rely on like a social worker or something to make that and ask them whether they're happy with that, they can use like letters or you know like somebody that's deaf, can you give you signals do you know what I mean? (MEN017).

\subsubsection{Participants Articulating their Decisions}

A key issue for many participants was not having the confidence to articulate their decision (or ask for support) or not being listened to/having their decision accepted. While there was acknowledgement that understanding/attitudes had changed from the past, for others, there were still difficulties in having their opinions considered in relation to medication etc.

I feel very confident that like if I have made my own decision and people accept it and then I would have felt I would have achieved something that hadn't really been 
achieved before, and that I wouldn't have not needed anybody else to go through while making that decision (MEN018).

Well, I knew exactly what I wanted. The main problem was getting them to understand but I did know exactly what I wanted, there was no doubt in my mind what I wanted, and that I was pursuing the only course I could to change the situation and how it worked for me, you know? (PRA004).

I had a few problems with a un-named agency who were wanting to disclose private information about me to people and ... this was in the last month or so like - but I tackled it myself. I wrote about four letters to the people involved and got them to change their point of view in the long run. I did take several weeks but I'm not going to disclose what the information was, or what it was about, but it was a fairly major ... about the most major situation. Now l'm not going to call it a question, but the situation was the most major l've had for many a long year. (PRA004).

Well that means like making decisions for myself with the help of staff and all in the house and my parents, well if I'm not sure of anything I would phone my mum and ask her what should I do about things like should I go to the pool or not, or should I eat in or not, or should I do my washing at the right time because I have different days for doing washing and then every day cooking as well, but I feel that sometimes I don't ask a lot of the staff and I should be more outgoing and be honest and say exact this is what I'm actually saying and being honest and that, say for example if they help me to clean my room or that they do one part, like for example they do the bathroom and I hoover and all and they wash the sink and 
that, but sometimes I do ask that but I can't change the bed sheets on my own, I can strip them but I would have to have help with that, and I feel I should be getting further of cleaning in the room, I feel I don't clean my bedroom hard enough to get it very well cleaned, get all the dust and all out, it's just being a bit more assertive about that and actually just saying, because sometimes l'm afraid to ask for help in case they're busy, or I want to save time, or I don't want to cause a fuss (MEN017).

One time I didn't want a particular member of staff supporting me, who was the assistant manager who came round to support me, but the service manager said in my review well you have put up with it or shut up you know you have to take him or that, but <name removed>, sorry, the social worker, said if I didn't want that particular person supporting me that should be respected.....It was respected, and it's different in supported living, you can't say you know it's quite difficult because there is 4 people and if you didn't get on with that particular member of staff and you didn't want them supporting it's not fair to say they can't come in at all because the other tenants might like that person, but they could come in at a different time when I wasn't there, but you see when I was on my own they were saying that you had to have a reason why you didn't want that person, but my social worker said if you didn't want that particular person then that should be respected (MEN017).

I've come to the point now and I've come to the doctors that I trust, the doctors now are more forward and more understanding, they will listen to you now, they will listen, if you feel the medication is not working you have a right to say that to the doctor now, years ago you hadn't that right, you had no say in the matter, and that's how 
forward it has come because it's more open now with mental health, it's more open with your sickness they're more respectable now and they respect you (PRA010).

The main problem I usually have on a day to day basis, is amount of medications they have me under. Mmm ... they've got me on quite a high dose of Clotiapine, they've got me on quite a high dose of sleeping tablets and they've got me on the (?Razapam 00:47)... mmm ... 4 times a day at the minute as well. Mmm, now l've been reasonably settled since March - things have been going ok - and I have asked my CPN and my psychiatrist on numerous occasions, almost every week, if I can come down off the (?Razapam) back on to my Diazepam, because that used to be used as a painkiller for my back as well. But they're saying no. Originally whenever they put me on, they changed the medications around. They'd said to me... mmm ... if you feel well enough to come off this, if you want to stop it, and you feel like, you know, you want your Clotiapine reduced down, or your sleeping tablet reduced down, then all you have to do is call us and let us know and we'll be fine with it. But now that they've got me on it, they're not agreeing to take me off it. So that's one of the major problems I'm having with them at the minute as it is (PRA001).

If I thought they were giving me too much medication I would say, that's far too much for me you know (PRA008). 


\subsection{Decision Making and Training}

Some participants described how training received had given them confidence to advocate for themselves, insight into their own situation which enabled them to appreciate that choices were available when taking decisions, additional skills and employment.

Well I feel if I knew it was going to affect me then I wouldn't be making that decision, I think that you see the qualifications that I have gained in regard to gaining them and I have actually been involved a few computer courses and I wouldn't have gotten my job if it weren't for knowing more about how to use computers and how to use them (MEN018).

Well I feel proud of myself because when I started doing this, the training, I would never have spoke up but now I'm getting the encouragement to speak up and guide people to their places now (MEN019).

I feel very lucky and very independent, because I know there is a lot of people who don't have the capacity to make the right decision and I think working in this environment helps me realise that, (MEN013).

Well you see I think if I had better grades I would have been able to maybe go through university because, but I hadn't actually known that there were places where you could train up for work instead of actually going away to university and leaving home for like a long period of time, but I didn't actually know there was places like that around <name of town removed $>$ where you could sort of train, and it was only 
that my mum had informed me about a place that they would support you to gain my qualifications (MEN018).

Well as I was growing up I wasn't really that confident about sort of making decisions on my own, I sort of relied more on my mum and dad to make decisions for me, but as I went to secondary school and sort of learned some subjects in depth and sort of was preparing for work experience, I was more inclined to make my own decisions because I was planning on getting to live on my own and live independently, so I needed to sort of make my own decisions there and then, and you know some decisions have been very easy to make and some decisions that were very difficult for me to accept and I did not go through with some of them decisions, now I did not go to university and gain any sort of degree, my parents sort of made that decision for me, because I wasn't able to get the grades through school that I wanted to get they were able to put me into a place where I was trained for work and get my NVQs and to be honest it has been very beneficial for me because the skills that I learned from my training for work it has enabled me to get a job, and in my job you actually do need to make some decisions for yourself, you need to be aware that there is people in a management role who would have to make their own decision whether to like say if they wanted you to stay on or maybe go somewhere else, but I was lucky that I had stayed on and I actually was employed in 2006 in one of my work placements and they had made that decision to let me work for them for quite a number of years (MEN018). 


\section{Discussion}

A general theme in this study was that participants found it relatively difficult to consider decision making ability in abstract terms and it tended to be when reflecting on specific decisions they had (or had not) made that they would talk more. It did, however, also reinforce that people whose decision making ability has been or is impaired can provide extremely helpful insights into what works for them. It also suggested that people have had very diverse experiences of support and that some aspects of support, such as developing the confidence to make decisions, could be further developed.

The findings also suggest that although people do not generally talk about their experiences of decision making and support in terms of the four main aspects of the assessment of capacity, it is possible to organise their experiences in this way. It also appears that support is not explicitly organised to address each aspect of people's functional ability to make a decision but also can usefully be considered in this way. One aspect of support which seems to present specific challenges is to promote people's ability to use and weigh the relevant information. Some participants did talk of the benefit of being presented with a list of possible options but there was little discussion of the process involved in using and weighing information to choose. There are immediate challenges for attempting to provide support on the relative risks and/or potential benefits of options, not least the challenge of accurately predicting the future consequences of decisions.

Nonetheless this would appear to be an aspect of support which could be better developed. This might include accessible explanations of probability and the use of 
info graphics, when there is research evidence to suggest relative likelihoods, to support the ability to use and weigh.

As identified consistently in the literature, the importance of the relationship with the supporter was repeatedly highlighted. Although this appears to be mainly highlighted when people have already established a trusting relationship over time it maybe also be useful to consider how this can be promoted even in circumstances when there isn't a pre-existing positive relationship.

\section{Conclusions}

The immediate implications of the study are perhaps mainly for the provision of support to make decisions and for training for supporters. It is reassuring that people's experiences do seem to reflect the four main components of the functional test but there remain challenges for how this can be most effectively achieved, especially perhaps about support for the ability to use and weigh. A further implication is the need for both support and training for supporters to actively consider the person's previous experiences and confidence about making decisions.

Acknowledgements: The research project was led by Praxis Care in partnership with Mencap NI and Queen's University Belfast and so the support of these three organisations is acknowledged. The project was informed at key points throughout the research process by an International Advisory Group which included specialist disabled and non-disabled researchers with expertise in this area. Advisory group members advised on issues such as the existing research, the interview schedule, data analysis and dissemination. 
References

Ahmed, K. et al. (2011). An audit of resuscitation status decisions in an older adult psychiatric unit. International Journal of Geriatric Psychiatry, 26(2), 214-216.

Antaki, C., Finaly, W.M.L., Walton, C. \& Pate, L. (2008). Offering choices to people with intellectual disabilities: An international study. Journal of Intellectual Disability Research, 52(12), 1165-1175.

Appelbaum, P.S. (2007). Assessment of Patients' Competence to Consent to Treatment. New England Journal of Medicine, 357, 1834-40.

Arstein-Kerslake, A., Watson, J., Browning, M., Martinis, J., \& Blanck, P. (2017). Future Directions in supported Decision Making. Disability Studies Quarterly, 37(1). Accessed at http://dsq-sds.org/article/view/5070/4549 on 3 September 2017

Bach, M. \& Kerzner, L. (2010). A New Paradigm for Protecting Autonomy and the Right to Legal Capacity. Toronto: Law Commission of Ontario.

Beamer, S., \& Brookes, M. (2001). Making decisions. Best practice and new ideas for supporting people with high support needs to make decisions. London: Values into Action.

Bigby, C., Douglas, J., Carney, T., Then, S. N., Wiesel, I., \& Smith, E. (2017).

Delivering Decision-making Support to People with Cognitive Disability-What has been learned from pilot programs in Australia from 2010-2015? Australian Journal of Social Issues, 52, 222-240. 
Braun, V., \& Clarke, V. (2006). Using thematic analysis in psychology. Qualitative Research in Psychology, 3(2), 77-101.

Carney, T. (2014). Clarifying, operationalising, and evaluating supported decision making models. Research and Practice in Intellectual and Developmental Disabilities, 1(1), 46-50.

Carney, T. (2017). Prioritising supported decision-making: running on empty or a basis for glacial-to-steady progress?. Laws, 6(4), 18.

Carney, T. \& Beaupert, F. (2013). Public and Private Bricolage - Challenges Balancing Law, Services and Civil Society in Advancing CRPD Supported DecisionMaking. UNSW Law Journal, 175, 175-201

Carter, B. (2009). Supported decision-making: Background and discussion paper. Melbourne: Office of the Public Advocate.

Chartres, D. and Brayley, J. (2010). Office of the Public Advocate South Australia: Submission to the Productivity Commission Inquiry into Disability Care and Support. Collinswood: Office of the Public Advocate.

Davidson, G., Kelly, B., Macdonald, G., Rizzo, M., Lombard, L., Abogunrin, O., CliftMatthews, V. \& Martin, A. (2015). Supported decision making: A review of the international literature. International Journal of Law and Psychiatry, 38, 61-67. 
Dawson, J. (2015). A realistic approach to assessing mental health laws' compliance with the UNCRPD. International Journal of Law and Psychiatry, 40, 70 - 79.

Dawson, C., \& McDonald, A. (2000). Assessing mental capacity-a checklist for social workers. Practice, 12(2), 5-20.

De Bhailís, C., \& Flynn, E. (2017). Recognising legal capacity: commentary and analysis of Article 12 CRPD. International Journal of Law in Context, 13(1), 6-21.

Department of Constitutional Affairs (2007). Mental Capacity Act 2005: Code of Practice. London: The Stationery Office.

Devi, N. (2013). Supported Decision-Making and Personal Autonomy for Persons with Intellectual Disabilities: Article 12 of the UN Convention on the Rights of Persons with Disabilities. Journal of Law, Medicine \& Ethics, Winter, 792 - 806.

Devi, N., Bickenbach, J., \& Stucki, G. (2011). Moving towards substituted or supported decision-making? Article 12 of the Convention on the Rights of Persons with Disabilities. European Journal of Disability Research, (5), 249 - 264.

Devi, N., Prodinger, B., Pennycott, A., Sooben, R., \& Bickenbach, J. (2019). Investigating Supported Decision-Making for Persons With Mild to Moderate Intellectual Disability Using Institutional Ethnography. Journal of Policy and Practice in Intellectual Disabilities. First published online, 03 November 2019, https://doi.org/10.1111/jppi.12314 
Donnelly, M. (2009). Best interests, patient participation and the Mental Capacity Act 2005. Medical Law Review, 17, 1-29

Dowling, S., Manthorpe, J. \& Cowley, S. (2007). Working on person-centred planning: from amber to green light? Journal of Intellectual Disabilities, 11(1), 65 82.

Dunn, M.C., Clare, I.C.H. and Holland, A.J. (2010), Living 'a life like ours': support workers' accounts of substitute decision-making in residential care homes for adults with intellectual disabilities. Journal of Intellectual Disability Research, 54, 144-160.

Elliot, J., Emerson, E., Hatton, C., Joyce, T., Knapp, M., Krijnen-Kemp, E., Mclntosh, B., Oakes, P., Robertson, J., Romeo, R. and Routledge, M., (2005). The Impact of Person Centred Planning. Lancaster: Institute for Health Research, Lancaster University.

Emmett, C, Poole, M, Bond, J et al (2013). Homeward bound or bound for a home? Assessing the capacity of dementia patients to make decisions about hospital discharge: comparing practice with legal standards. International Journal of Law and Psychiatry, 36, 73-82

Flynn, E., \& Arstein-Kerslake, A. (2014). Legislating personhood: Realising the right to support in exercising legal capacity. International Journal of Law in Context, 10(1), 81-104.

Goldsmith, L., Skirton, H. \& Webb, C. (2008). Informed consent to healthcare interventions in people with learning disabilities--an integrative review. Journal of Advanced Nursing, 64(6), 549 - 563. 
Goss, C., Morett, F., Mazzi, M. A., Picolo, L .D., Rimondi, M., \& Zimmermann, C. (2008). Involving patients in decisions during psychiatric consultations. British Journal of Psychiatry, 193, 416 - 421.

Gregory, R., Roked, F., Jones, L. \& Patel, A. (2007). Is the degree of cognitive impairment in patients with Alzheimer's disease related to their capacity to appoint an enduring power of attorney? Age and Ageing, 36, 527-531

Hamann J, Mendel R, Cohen R, Heres S, Ziegler M, Buhner M, Kissling W. (2009) Psychiatrists' use of shared decision making in the treatment of schizophrenia: patient characteristics and decision topics. Psychiatric Services, 60(8), 1107-1112.

Hoole, L., \& Morgan, S. (2011). 'It's only right that we get involved': service $\square$ user perspectives on involvement in learning disability services. British Journal of Learning Disabilities, 39(1), 5-10.

House of Lords (2014). Mental Capacity Act 2005: post-legislative scrutiny. London: The Stationery Office Ltd.

Jamieson, R., Theodore, K. \& Raczka, R. (2015). Becoming a mother: Supported decision making in context. Journal of Intellectual Disabilities, 20(4), 313-328.

Kerr, I. and Gruben, V. (2019) Als as Substitute Decision-Makers. Yale Journal of Law and Technology, Special Issue 78, 1-20.

Kokanović, R., Brophy, L., McSherry, B., Flore, J., Moeller-Saxone, K., \& Herrman, H. (2018). Supported decision-making from the perspectives of mental health service 
users, family members supporting them and mental health practitioners. Australian \& New Zealand Journal of Psychiatry, 52(9), 826-833.

Knox, L., Douglas, J.M. \& Bigby, C. (2015). Becoming a decision-making supporter for someone with acquired cognitive disability following traumatic brain injury. Research and Practice in Intellectual and Developmental Disabilities, 3(1), 12-21.

Mackenzie, R. \& Watts, J. (2011). Can clinicians and carers make valid decisions about others' decision-making capacities unless tests of decision-making competence and capacity include emotionality and neurodiversity? Tizard Learning Disability Review, 16, 43-51.

Menezes, B. \& Tadros, G. (2008). Implementing the Mental Capacity Act in nursing homes: between obligation and application. International Journal of Geriatric Psychiatry, 23, $334-335$.

Mental Health Foundation (2012). Mental Capacity and the Mental Capacity Act 2005: A Literature Review. London: Mental Health Foundation.

Morrissey, F. (2012). The United Nations Convention on the Rights of Persons with Disabilities: A New Approach to Decision-Making in Mental Health Law. European Journal of Health Law, (19), 423-440.

National Institute for Health and Care Excellence (NICE) (2018) Decision-making and mental capacity. Manchester and London: NICE. 
Patel, S. \& Bakken, S. (2010). Preferences for Participation in Decision Making Among Ethnically Diverse Patients with Anxiety and Depression. Community Mental Health Journal, 46, 466-73.

Quinn, G. (2010) Personhood \& Legal Capacity: Perspectives on the Paradigm Shift of Article 12 CRPD. Paper presented at Conference on Disability and Legal Capacity under the CRPD, Harvard Law School, Boston, 20 February 2010. Online at http://www.inclusionireland.ie/documents/HarvardLegalCapacitygadraft2.doc. Accessed 16th October 2011.

Ramasubramanian, L., Ranasinghe, N., \& Ellison, J. (2011). Evaluation of a structured assessment framework to enable adherence to the requirements of Mental Capacity Act 2005. British Journal of Learning Disabilities, 39(4), 314-320.

Redley, M., Claire, I.C.H., Dunn, M.C., Platten, M. and Holland, A.J. (2011). Introducing the Mental Capacity Advocate (IMCA) Service and the Reform of Adult Safeguarding Procedures. British Journal of Social Work, 41(6), 1058-1069.

Samsi, K., Manthorpe, J., Nagendran, T. and Heath, H. (2012), Challenges and expectations of the Mental Capacity Act 2005: an interview $\square$ based study of community-based specialist nurses working in dementia care. Journal of Clinical Nursing, 21: 1697 - 1705.

Stone, M., Kokanovic, R., Callard, F., \& Broom, A. F. (2020). Estranged relations: coercion and care in narratives of supported decision-making in mental healthcare. Medical Humanities, 46(1), 62-72. 
Victorian Law Reform Commission (2011) Guardianship: Consultation Paper 10. Melbourne: Victorian Law Reform Commission.

United Nations (2006) Convention on the Rights of Persons with Disabilities. New York: United Nations.

Watson, J., \& Joseph, R. (2015). People with severe or profound intellectual disabilities leading lives they prefer through supported decision-making: Listening to those rarely heard. A guide for supporters. A training package developed by Scope. Melbourne: Scope.

Webb, P., Davidson, G., Edge, R., Falls, D., Keenan, F., Kelly, B., McLaughlin, A., Montgomery, L., Mulvenna, C., Norris, B. \& Owens, A. (2020). Service users' experiences and views of support for decision-making. Health \& Social Care in the Community, First published online on 23 February 2020, https://doi.org/10.1111/hsc.12961.

Willner, P., Bridle, J., Price, V., Dymond, S., \& Lewis, G. (2013). What do NHS staff learn from training on the Mental Capacity Act (2005)? Legal and Criminological Psychology, 18(1), 83-101.

Willner, P., Smith, M., Payne-O Donnell, P., Parry, R., \& Jenkins, R. (2007). When should clinical psychologists be involved in assessment of mental capacity? Recommendations from a learning disability service. Clinical Psychology Forum, $180,30$. 
Wong, J. G., Clare, I. C., Holland, A. J., Watson, P. C., \& Gunn, M. (2000). The capacity of people with a 'mental disability' to make a health care decision. Psychological Medicine, 30(2), 295-306. 